\title{
ParalOhde!?
}

\section{AS HISTÓRIAS DE VIDA DOS FILHOS SEPARADOS PELA "LEPRA" NO ESPÍRITO SANTO•}

\author{
The life stories of children separated by "leprosy" in the Holy Spirit \\ Elaine Cristina Rossi Pavani* \\ *Doutoranda da UFES - elainecristinarossi@hotmail.com
}

\author{
Recebido em 06/06/2019. Aceito para publicação em 30/07/2019. \\ Versão online publicada em 10/09/2019 (http://seer.ufrgs.br/paraonde)
}

\section{Resumo:}

O presente estudo aborda a temática dos filhos indenes dos "leprosos" que foram internados compulsoriamente no Educandário Alzira Bley em Cariacica-ES, no período entre 1937-1979, devido a legislação vigente para o período. O método utilizado para explicitar as condições de vida dentro da instituição e as marcas deixadas na memória dos egressos foi a história de vida.

Palavras-chave: Lepra; isolamento compulsório; Educandário Alzira Bley.

\begin{abstract}
:
The present study deals with the issue of the indigent children of the "lepers" who were compulsorily hospitalized at the Alzira Bley School in Cariacica-ES, in the period between 1937-1979, due to the legislation in force for the period. The method used to explain the conditions of life within the institution and the marks left in the memory of the graduates was the life story.
\end{abstract}

Key-words: Leprosy; compulsory isolation; institution Alzira Bley.

\section{Introdução}

A "lepra" sempre foi vista pela sociedade como uma ameaça e, por muito tempo, a única solução para o problema era o isolamento compulsório. No Brasil, Getúlio Vargas (1934) lança o "Plano Nacional de Combate à Lepra", que previa a construção de leprosários em todos os estados brasileiros. Tal plano se alicerçava no tripé: leprosários (para os infectados), dispensários (para os comunicantes) e preventórios (para os filhos indenes) (CABRAL, 2013). No Espírito Santo (ES) foram construídos o Hospital Colônia Pedro Fontes, também conhecido como Colônia de Itanhenga e o Educandário Alzira Bley, localizados às margens da BR-101, km 9, Cariacica-ES. Os oito dispensários localizavem-se em: Vitória, Colatina, Afonso Claudio, Alegre, Muqui, São José do Calçado, Mimoso do Sul e Cachoeiro de Itapemirim. O Educandário foi inaugurado em 11 de abril de 1937 com a finalidade de acolher os filhos indenes encaminhados para lá por meio de medidas regulamentares, conforme o art. 148 do

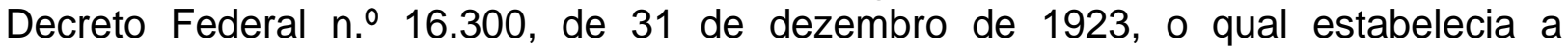
segregação imediata dos filhos dos leprosos logo após o nascimento nos hospitaiscolônia. Posteriormente outras leis que seguiram a mesma política de segregação e isolamento dos filhos dos leprosos foram publicadas até 1962.

$\mathrm{O}$ isolamento compulsório das pessoas atingidas pela hanseníase e de seus filhos nos preventórios baseou-se em teorias científicas (sanitarismo / higienismo / eugenismo) que o legitimavam, e em um contexto de maior controle estatal sobre os assuntos

\footnotetext{
- Artigo originalmente apresentado na XII ENANPEGE.
} 
nacionais, por meio de velhos mecanismos autoritários e da força do aparelho de Estado. Durante o governo Juscelino Kubitschek foi criada a Campanha Nacional Contra a Lepra e também foram tomadas iniciativas de descentralização das atividades de controle da doença para unidades estaduais de saúde. $\mathrm{Na}$ década seguinte, teve início a campanha pela mudança do nome da doença no Brasil objetivando a desestigmatização. O médico e professor universitário Abrahão Rotberg propôs substituir a palavra lepra por hanseníase.

A partir de 1980, o uso da Poliquimioterapia (PQT) foi aconselhado para o tratamento de todas as pessoas com hanseníase no mundo. Dentro deste contexto houve também o fim do isolamento compulsório dos filhos indenes que habitavam os educandários. Estes, por sua vez, foram (re)introduzidos na sociedade. Segundo o relatório preliminar da Secretaria de Direitos Humanos da Presidência da República (25/09/2012), sobre os filhos segregados de pais portadores de "lepra" submetidos à política de isolamento compulsório, estima-se que mais de 33.689 crianças foram isoladas ao longo de 59 anos, período que durou o isolamento dos filhos. No ES são mais de mil crianças. Este trabalho tem o objetivo de averiguar as condições de vida oferecidas às crianças no Educandário Alzira Bley, bem como apresentar as histórias de vida de quatro egressos que sofreram alienação parental, ao serem privados da convivência com seus pais e outros familiares. Visa também retratar como era a vida dentro desta instituição total ${ }^{1}$.

\section{Desenvolvimento}

Quem olha a fachada histórica e imponente de jeito tão decadente, com ares de abandono, que não é pintada há mais de 20 anos, não imagina o quanto 0 Educandário Aliza Bley foi, e ainda é, importante para milhares de pessoas (Foto 1). A preservação do patrimônio histórico se confunde com a preservação das vidas daqueles que por ali passaram durante a internação compulsória. Ora pela falta de oportunidades, ora pelo descaso governamental.

\section{Foto 1 - Fachada da entrada principal do Educandário Alzira Bley.}

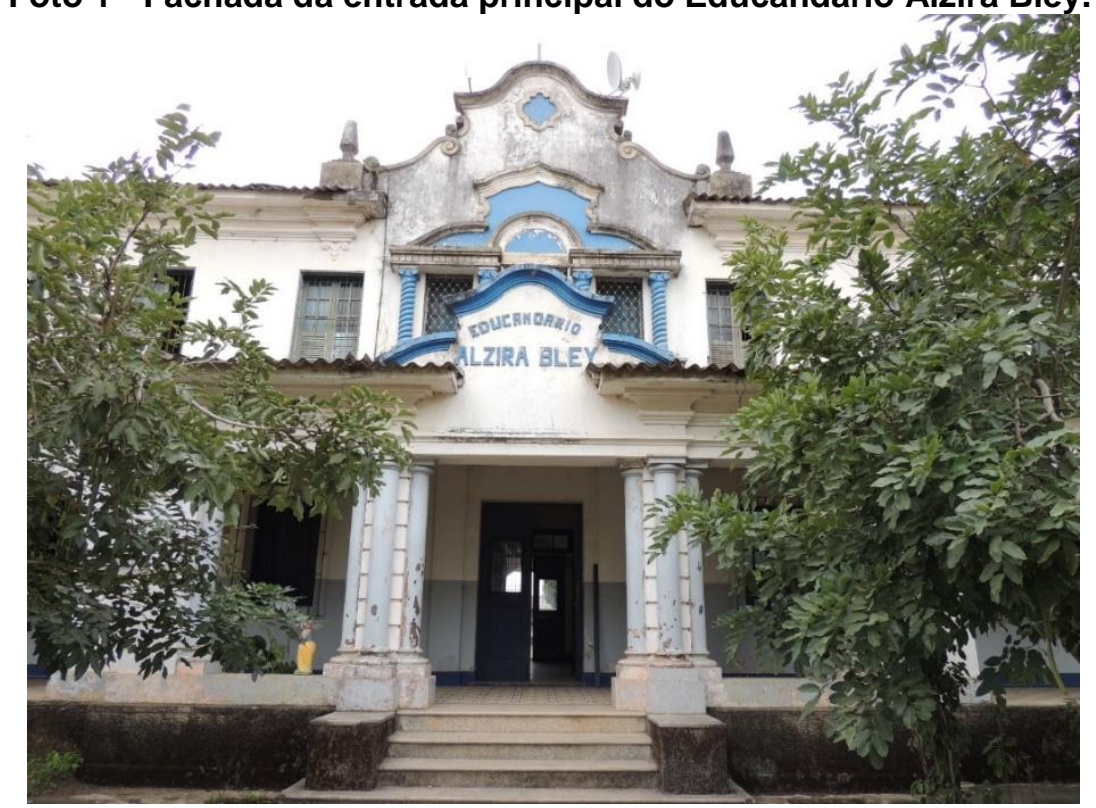

Fonte: Registro fotográfico da autora em pesquisa de campo realizada em 21/07/2016

\footnotetext{
${ }^{1}$ Os preventórios e/ou educandários correspondiam ao que Goffman denomina de "Instituição Total" onde as pessoas vivem como internos e todos os aspectos de sua vida são realizados naquele local, sob a mesma autoridade, intramuros. Eram como um dos tipos de instituição fechada que o autor descreve como "locais estabelecidos para cuidar de pessoas incapazes de cuidar de si mesmas e que são também uma ameaça à comunidade, embora de maneira não intencional; sanatórios para tuberculosos, hospitais para doentes mentais e leprosários" (GOFFMAN, 2015, p. 17).
} 
Muitas vidas passaram pela porta azul (Foto 2) caminhando com seus próprios passos, em geral, crianças ainda pequenas e inocentes, sem saberem o que estava verdadeiramente acontecendo, outros ainda, enrolados nos cueiros, logo após seus primeiros sopros de vida. O que eles tinham em comum? Uma história marcada pela hanseníase, pela separação dos seus pais e entes queridos, pelo estigma e o preconceito que os acompanhariam a vida inteira.

Em 79 anos, quase oito décadas depois, quase nada mudou. As mesmas paredes largas, brancas e frias. As imensas portas e janelões de madeira pintados de azul escuro e o azulejo original. Os móveis, as molduras das fotos em preto e branco das presidentes e o velho relógio de ponto a controlar as horas que passam e as pessoas, umas para o trabalho e outras para ficarem. As marcas do tempo e da história de vida de muitas pessoas estão presentes neste lugar de memória. Como afirma Pollak: "existem lugares da memória, lugares particularmente ligados a uma lembrança, que pode ser uma lembrança pessoal, mas também pode não ter apoio no tempo cronológico" (POLLAK, 1992, p. 201).

Algumas crianças que passaram por essa porta azul (Foto 2) nunca mais tiveram contato com o mundo externo. Alguns recém-nascidos não resistiram às ausências e faleceram. Outros, porém, resistiram até o fim do período de internação compulsória em 1979 e foram gradativamente sendo (re) inseridos na sociedade até, aproximadamente, 1985. Para muitos, a grande porta azul representou um rompimento da relação afetiva entre pais e filhos como narra Esmeralda.

\begin{abstract}
Eu só sei que, quando a minha mãe era doente da hanseníase, era assim, nasceu dela foi direto para o orfanato porque não podiamos ficar com ela. Eram arrancados e ficavam lá. Então, eu nunca chamei a minha mãe de mamãe até hoje e nem meu pai de papai. Não tínhamos costume com eles e nem eles tinham amor a gente e eu também não tinha amor a eles (Narrativa da ex-interna Esmeralda).
\end{abstract}

À esquerda, temos a porta de acesso à sala de reuniões, onde o destino de muita gente foi traçado e decidido por quem tinha o controle da situação. À direita, a porta do depósito debaixo da escada. Alguns ex-internos citam um "quartinho escuro", onde eram colocados de castigo, cujos indícios ${ }^{2}$ nos levam a suspeitar desse cômodo debaixo dessa escada.

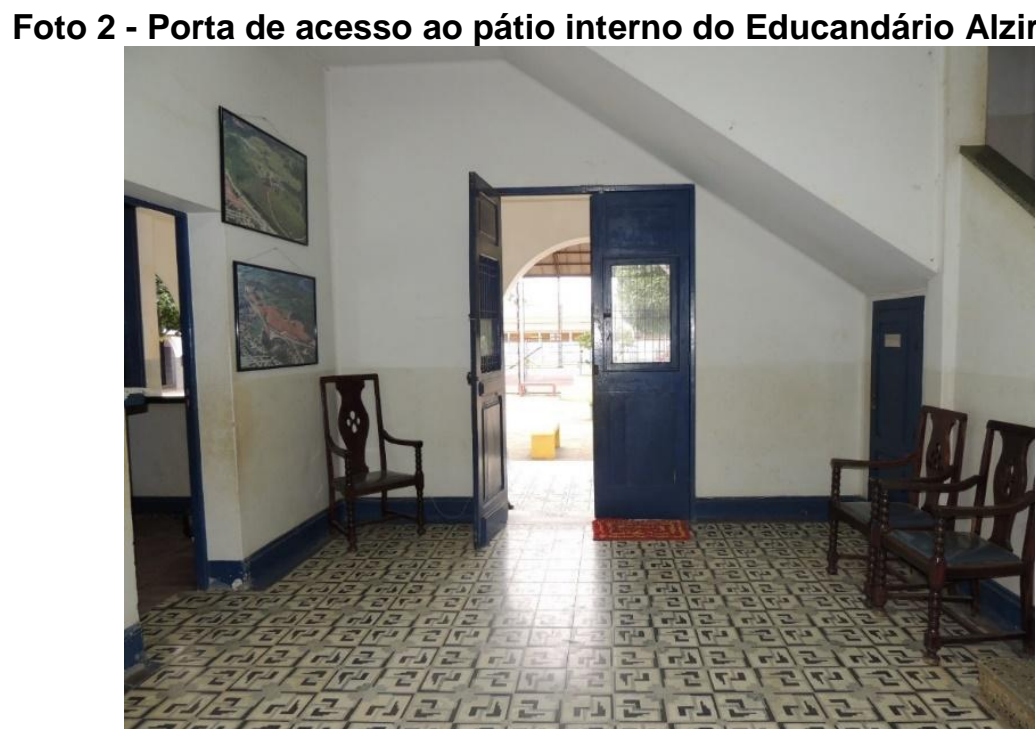

Fonte: Registro fotográfico da autora em pesquisa de campo realizada em 21/07/2016

\footnotetext{
${ }^{2}$ GINZBURG, Carlo. O método indiciário.
} 
De acordo com o livro de registros do Educandário, aproximadamente 1.175 crianças e adolescentes entraram nessa instituição no período em que seus pais/familiares eram internados compulsoriamente no Hospital Colônia Pedro Fontes (1937 a 1979). Desse montante, são registradas 103 mortes, estando os demais, (1.072 pessoas) com idades entre 38 e 96 anos, atualmente, convivendo em nossa sociedade, marcados por suas histórias, com diferentes trajetórias após sua saída dessa instituição. Famílias inteiras foram marcadas pelo estigma ${ }^{3}$ da "lepra".

Algumas dessas famílias foram constituídas dentro do Hospital Colônia Pedro Fontes, com a união de pessoas infectadas pelo bacilo Mycrobacterium leprae. Outras foram internadas juntas, pois o casal era portador da doença. Na segunda situação, se o casal tivesse filhos sadios, estes seriam encaminhados para o Educandário Alzira Bley. Em todas as situações de crianças que foram geradas e concebidas dentro do Hospital, no período de internações compulsórias, o destino era o Educandário conforme explicito do

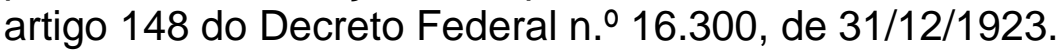

Art. 148. Nos estabelecimentos de leprosos, além das disposições já determinadas e das que forem prescritas em seus regimentos internos, serão observadas mais as seguintes:

f) os filhos de leprosos, embora um só dos progenitores seja doente, serão mantidos em secções especiais, anexas às áreas de pessoas sãs do estabelecimento, para onde serão transportados logo depois de nascidos;

g) essas mesmas crianças não deverão ser nutridas ao seio de uma ama e não serão amamentadas pela própria mãe se esta for leprosa;

Tal medida foi vivenciada na realidade por Topázio que nasceu no Hospital Colônia Pedro Fontes em dezoito de setembro de 1957 e foi encaminhado diretamente para o Educandário após o parto.

Naquela época, os pais da gente podiam ser doentes, mas os filhos nasciam perfeitos, eu só me contaminaria, assim diz a regra, se eu mamasse na minha mãe, se eu mamasse nela. Não podia mamar. Eu nasci e fui separado na hora e levado direto para o Educandário Alzira Bley, com zero ano (Narrativa do ex-interno Topázio).

Outras leis reforçavam essa separação dos filhos sadios de seus progenitores hansenianos, como a Lei n. 610, publicada no dia 13/01/1949, que vigorou até 1969 e fixava, em seus arts. 15 e 16, que todo recém-nascido ou filhos de leprosos deveriam ser assistidos em preventórios. As regras que determinavam a separação imediata dos recém-nascidos de seus pais também estavam presentes no artigo 10 do Decreto $\mathrm{n} .{ }^{\circ}$ 968, de 07/05/1962.

Em virtude desse cenário político, sanitário e social que abrangia todo território nacional, os filhos do casal Diamante e Turquesa, ambos leprosos e internos da Colônia de Itanhenga, foram encaminhados para o Educandário Alzira Bley logo após o nascimento, sem ao menos serem amamentados pela mãe. No quadro 1, é apresentada a prole do casal. Suas identidades foram preservadas, a fim de manter o caráter científico deste trabalho e a privacidade da família.

${ }^{3}$ GOFFMAN, Erving. O termo estigma, portanto, será usado em referência a um atributo profundamente depreciativo, mas o que é preciso, na realidade, é uma linguagem de relações e não de atributos. Um atributo que estigmatiza alguém pode confirmar a normalidade de outrem, portanto ele não é, em si mesmo, nem honroso nem desonroso (1988, p. 13). 
Quadro 1 - Prole do Casal Diamante e Turquesa, nascidos no Hospital Colônia Pedro Fontes, Itanhenga - Cariacica/ES.

\begin{tabular}{|c|c|c|c|c|c|c|c|}
\hline \multirow{2}{*}{ № } & \multirow{2}{*}{$\begin{array}{c}\text { Nome } \\
\text { Fictício }\end{array}$} & $\begin{array}{c}\text { Parentesc } \\
\text { o }\end{array}$ & $\begin{array}{c}\text { Ano } \\
\text { Nasc. }\end{array}$ & $\begin{array}{c}\text { Idade } \\
\text { em } \\
\mathbf{2 0 1 7}\end{array}$ & Sexo & $\begin{array}{c}\text { Tempo } \\
\text { Interno } \\
\text { (Anos) }\end{array}$ & Residência atual \\
\hline 1 & Ametista & Filha & 1955 & 62 & $\mathrm{~F}$ & 17 & Hospital Pedro Fontes \\
\hline 2 & Topázio & Filho & 1957 & 60 & $\mathrm{M}$ & 13 & Vila Velha \\
\hline 3 & Jade & Filha & 1957 & 59 & $\mathrm{~F}$ & 22 & Cariacica \\
\hline 4 & Granada & Filho & 1958 & ------ & $\mathrm{M}$ & 4 & Faleceu \\
\hline 5 & Opala & Filho & 1959 & 58 & $\mathrm{M}$ & 19 & Hospital Pedro Fontes \\
\hline 6 & Esmeralda & Filha & 1961 & 56 & $\mathrm{~F}$ & 13 & Cariacica \\
\hline 7 & Safira & Filho & 1963 & 54 & $\mathrm{M}$ & 18 & Vila Velha \\
\hline 8 & Rubi & Filha & 1968 & 49 & $\mathrm{~F}$ & 3 & Vila Velha \\
\hline 9 & Turmalina & Filha & 1972 & 45 & $\mathrm{~F}$ & 3 & Cariacica \\
\hline
\end{tabular}

Fonte: Banco de dados da autora construído a partir do livro de registros doEducandário Alzira Bley do período de 1937 a 1979 e das histórias orais.

Todos os nove filhos do casal foram levados após o nascimento para o Educandário Alzira Bley. Granada faleceu por conta de meningite com pouco mais de quatro anos de idade. Os oito filhos que foram inseridos na sociedade, após o término da internação compulsória, residem na Região Metropolitana da Grande Vitória. Sendo a primogênita, a responsável pelos cuidados com a mãe, que ainda mora em uma das 53 casas da antiga "Colônia de Itanhenga".

No intuito de conhecer o cotidiano dos internos do Educandário, bem como sua inserção na sociedade após o término do período compulsório, foi adotada como metodologia a história oral ${ }^{4}$ de vida. Os relatos das histórias de vida de quatro irmãos da família das pedras preciosas foram gravados no dia 12 de Junho de 2016, em CariacicaES. Os narradores assinaram o Termo de Consentimento Livre e Esclarecido (TCLE). Para manter o anonimato dos entrevistados, optou-se por identifica-los por nomes de pedras preciosas, conforme quadro 1.

Os registros sobre a vida nos educandários brasileiros são poucos e sobre o Educandário Alzira Bley, no Espírito Santo, ainda não havia relatos sobre a vida intramuros nesta instituição total. Portanto, a história oral contribui para revelar eventos desconhecidos, áreas inexploradas e grupos minoritários, como aponta Portelli.

A primeira coisa que torna a história oral diferente, portanto, é aquela que nos conta menos sobre eventos que sobre significados. Isso não implica que a história oral não tenha validade factual. Entrevistas sempre revelam eventos desconhecidos ou aspectos desconhecidos de eventos conhecidos: elas sempre lançam nova luz sobre áreas inexploradas da vida diária das classes não hegemônicas. Deste ponto de vista, o único problema colocado pelas fontes orais é aquela da verificação (PORTELLI, 1997, p. 31).

A palavra chave aqui é a possibilidade de apresentar a história de vida de quatro dos oito filhos do casal Diamante e Turquesa, a saber: Topázio, Jade, Esmeralda e Safira. Retratar suas histórias de vida significa transpor, para o plano textual

a representatividade das fontes orais e das memórias, que se mede pela capacidade de abrir e delinear o campo das possibilidades expressivas. No plano dos conteúdos, mede-se não tanto pela reconstrução da experiência concreta, mas pelo delinear da

\footnotetext{
${ }^{4}$ THOMPSON, Paul. A possibilidade de utilizar a história para finalidades sociais e pessoais construtivas desse tipo vem da natureza intrínseca da abordagem oral. Ela trata de vidas individuais - e todas as vidas são interessantes. E baseia-se na fala, e não na habilidade da escrita, muito mais exigente e restritiva. Além disso, o gravador não só permite que a história seja registrada em palavras faladas, mas também que seja apresentada por meio delas (1998, p. 41).
} 
esfera subjetiva da experiência imaginável: não tanto o que acontece materialmente com as pessoas, mas o que as pessoas sabem ou imaginam que possa suceder. E é o complexo horizonte das possibilidades o que constrói o âmbito de uma subjetividade socialmente compartilhada (PORTELLI, 1996, p. 7-8).

A infância, a adolescência e, para alguns, até a juventude foram segregadas de seus pais. Esmeralda e Topázio ficaram no Educandário por 13 anos, enquanto seus irmãos Safira e Jade ficaram 18 e 22 anos, respectivamente. A reminiscência destes filhos sobre seus pais são recordações de distanciamento, de pessoas que lhes eram apresentadas por meio de telas e a certa distância como narram Topázio e Esmeralda.

Eu fazia visita uma vez por ano. A gente ia a pé. Quando a gente chegava lá, se você perguntasse quem era meu pai e minha mãe eu não sabia quem era na época. [...] Tinham três camadas de telas, você não podia ter contato! Não podia ter contato. Eles mostravam assim, seu pai e sua mãe são aqueles de lá, via de longe, podiam chegar perto assim, mais tinha a camada de tela que separava (Narrativa do ex-interno Topázio).

Só visitava quando era dia das mães e dia dos pais que nós íamos lá. Aí, o pessoal do orfanato levava a gente lá para visitar, mas era tudo fechado de tela. Não era de chegar e abraçar não. Era enfiado o dedinho na tela (Narrativa da ex-interna Esmeralda).

Como as crianças eram retiradas dos pais logo após o nascimento, elas não tinham contato nem convívio com eles. A apresentação das crianças aos pais só era realizada quando elas já estavam com idade de caminhar sozinhas até a Colônia para vê-los através da tela, onde lhes eram apontados: aqueles são seus pais. Outros trabalhos ${ }^{5}$ dessa natureza indicam que não havia interesse algum dos presidentes dos educandários em preservar os laços familiares destas crianças. Isso gerava grande sofrimento nos pais, que buscavam notícias sobre seus filhos.

Os ex-internos compartilham memórias sobre vários assuntos, como era a alimentação no Educandário, por exemplo:

Não era muito boa não. Tem dia que a gente nem comia direito. Porque lá era triguilho, bofe, né, assim. Só dia de domingo que a comida era mais gostosa. Eles faziam um pedacinho de galinha para cada um, arroz e feijão (Narrativa da ex-interna Esmeralda). A alimentação era o básico arroz, feijão, triguilho, canjiquinha. Mas a gente não deixava de se alimentar (Narrativa do ex-interno Safira).

A alimentação nossa era triguilho, canjiquinha, não tinha esse negócio de carne, arroz, coisa não. Era assim, bucho, bofe, miolo de boi. [...] O que vinha a gente comia (Narrativa da ex-interna Jade).

Não era boa não. Mas a gente comia. Comia canjiquinha com bicho e tudo, alface. A gente não ligava para essas coisas não, a gente queria é matar a fome (Narrativa do ex-interno Topázio).

Alimentos como o triguilho, a canjiquinha e o bofe, aparecem em praticamente todos os relatos. A alimentação, como um fator de fundamental importância para o desenvolvimento físico, intelectual e social das crianças, também ocupa a posição de destaque como um fator constitutivo de memória: os sabores da infância, o gosto de um almoço de domingo. "O que está em jogo na memória é também o sentido de identidade

\footnotetext{
${ }^{5}$ SANTOS, Cláudia Cristina dos Santos. Crianças Indesejadas: Estigma e exclusão dos filhos sadios de portadores de hanseníase internados no Preventório Santa Terezinha 1930-1967. 2009. 216 f. Dissertação de Mestrado em História Social. USP: Faculdade de Filosofia, Letras e Ciências Humanas. São Paulo, 2009.

SILVEIRA, Bruna Alves. Práticas sociais, memória e vivências no combate à lepra: isolamento compulsório em asilos-colônias e preventórios brasileiros - 1935 a 1986. 2013. 159 f. Dissertação de Mestrado em História. Universidade Federal de Uberlândia. Uberlândia, 2013.

CABRAL, Ana Michele de farias. Vivências compartilhadas de filhos separados pela hanseníase no RN a luz da história oral de vida. 2013. 143 f. Dissertação de Mestrado em Enfermagem. Universidade Federal do Rio Grande do Norte. Natal, 2013.
} 
individual e do grupo" (POLLAK, 1989, p. 10). Para o geógrafo Paul Claval, a lembrança dos lugares é também ligada aos sabores das comidas e aos demais órgãos dos sentidos como o olfato e o olhar.

\begin{abstract}
Nossa experiência espacial aparece inicialmente como visual. São muitos os trabalhos versando sobre o papel do olhar na construção do espaço e no seu controle: advinda da obra de Michel Foucault (1976), essa temática ocupa um papel fundamental. Entretanto, os cheiros dão aos lugares parte de suas especificidades. A lembrança dos lugares é também ligada aos sabores das comidas locais, da vegetação queimada e da terra úmida depois da chuva. Outrossim, a experiência corporal muda com a idade e com o sexo, apresentando-se a necessidade de explorar as geografias dos meninos, das mulheres e dos velhos (CLAVAL, 2002, p. 23).
\end{abstract}

Os relatos dos narradores apontam para os acontecimentos que ficaram na memória como frutos de um processo seletivo/construtivo, no qual os temas são selecionados e ressignificados por meio da subjetividade. Sendo assim, "a memória é um elemento essencial do que se costuma chamar identidade, individual ou coletiva, cuja busca é uma das atividades fundamentais dos indivíduos e das sociedades de hoje" (LE GOFF, 1994, p. 472).

A história de vida das pessoas, que viveram como internas do Educandário Alzira Bley, alterna elementos de identidade individual e coletiva. Apesar das características próprias de cada indivíduo, seus gostos, suas preferências, vontades e necessidades havia a imposição de uma rotina organizada para manter uma instituição como o Educandário funcionando. Tudo isso, exigia dessas crianças e jovens uma vida coletiva, com pouca ou nenhuma privacidade, muitas regras, rigor, trabalho e castigos, físicos e psicológicos, como relatam os ex-internos:

\begin{abstract}
A vida lá, nossa, foi uma vida conturbada. Sem ter o afeto do pai e da mãe. A gente era subordinado aos mais velhos. Tinha aquela hierarquia. A gente ia crescendo, tomando certa idade, e iria um olhando o outro. A gente estudava, trabalhava. Mexia com plantação, horta. Tinha a área de lazer de futebol. A área escolar, porque a gente tinha um período de escola, está era a nossa rotina. Ficava preso ali dentro, sem ver o mundo lá fora (Narrativa do ex-interno Safira).

Olha, eu gostava, assim, eu fui tratada muito bem lá. Nós éramos tudo uma turma, um montão de gente que morava lá. Eu gostava de lá (Narrativa da ex-interna Esmeralda). Porque nossa vida nossa foi assim: fomos crescendo, fomos trabalhando, aprendemos corte e costura, artesanato, pelo menos eu aprendi alguma coisa. Cozinhar, costurar. Eu ainda faço uma costura (Narrativa da ex-interna Jade).
\end{abstract}

Apesar de muitos ex-internos relatarem maus tratos e sofrimentos durante o período em que estiveram no Educandário, a instituição representou para essas 1.072 crianças a única opção de abrigo, alimento, infância segura e sadia fora das ruas e dos constrangimentos a que estariam submetidos, naquela época, em virtude do estigma da "lepra". "Mas esses exemplos têm em comum o fato de testemunharem a vivacidade das lembranças individuais e de grupos durante dezenas de anos, e até mesmo séculos" (POLLAK, 1989, p. 8). Eles relataram ainda que os alojamentos continham, aproximadamente, 25 camas cada, que eram separados por sexo e faixa etária. As roupas que usavam vinham de doações e eram lavadas em uma lavanderia que ficava ao lado do prédio principal do Educandário. As crianças ajudavam nas atividades da lavanderia, varrer o pátio, capinar o pomar, arrumar as camas, lustrar os corredores, lavar as panelas, cuidar dos mais novos, lavar os banheiros, atividades estas denominadas como terapia ocupacional.

A idade e os motivos pelos quais cada um deixou o Educandário eram vários. Mas, para todos, representava um novo recomeço. Uns tinham para onde ir, outros não. As 
incertezas e as dificuldades eram constantes. Trezentas e trinta crianças, que entraram recém-nascidas, teriam o primeiro contato com 0 mundo externo aos muros do Educandário. No período de internação, algumas crianças foram retiradas por parentes ou "pessoas autorizadas" por juízes. Outras, saíram para servir ao exército, ou ainda, saíram porque atingiram a maior idade e não podiam permanecer mais no Educandário. A partir de 1979, com o fim da internação compulsória dos "leprosos" no Hospital Colônia Pedro Fontes, aqueles pais que ainda tinham condições físicas e saúde para reestabelecer a guarda de seus filhos, retiraram-nos do Educandário e foram morar em bairros periféricos de Cariacica ou numa determinada parte da Colônia, que foi desmembrada e loteada para construção de um bairro para os ex-internos do Hospital. Em todos os casos, a vida dessas pessoas, após a saída do Educandário não foi nada fácil. Questionados sobre para onde foram, eles responderam:

Para casa dos outros, casa de família, lá em Laranjeiras. Depois disso eu fiquei deprimida numa casa com muita gente, nós éramos igual um bicho do mato, não gostava de ficar assim numa montoeira de gente não. A gente gostava de ficar no canto da gente quietinha e fazendo as coisas, trabalhando. Casei agora, na idade com 33 anos. Foi assim namorei, daqui a dois ou três meses casei, fui no cartório e casei. No dia 22, agora, de junho vou fazer 25 anos de casada e vou vivendo a minha vida. Casei por casar, sabe porquê. Eu sofri muito, eu sofri (Narrativa da ex-interna Jade). Depois que eu completei 18 anos, eu tenho o meu irmão mais velho que morava em república, aí eu fui morar com ele. Sai dali, consegui um estágio na Caixa Econômica, estagiei dois anos, depois entrei no Banco do Bradesco. Trabalhei 8 anos de bancário. Trabalhei no Hotel Porto do Sol, depois eu trabalhei numa empresa Vitória Aduaneira de Importação e Exportação, eu era da área de recursos humanos, RH. Departamento pessoal (Narrativa do ex-interno Safira).

Além de todas as dificuldades enfrentadas na separação imediata dos pais ao nascer, de crescer tão perto e tão distante ao mesmo tempo dos seus progenitores, que nunca passaram pela grande porta azul para buscá-los, para além de todas as privações do internato, ao serem devolvidos à sociedade. Ainda tiveram de enfrentar o estigma e o preconceito social, como aponta Topázio.

Eu fui vítima de preconceito quando eu fui servir ao exército, me alistar. Eles perguntaram assim, onde você nasceu? Eu nasci em Cariacica, em Itanhenga. Então é filho de leproso. Aí você vai fazer o quê? (Narrativa do ex-interno Topázio).

Compreendemos que as histórias de vida são muito difíceis de serem reconstituídas com riquezas de detalhes, datas e cenas. Até porque, como afirma Pollak, "a memória é seletiva, nem tudo fica gravado. Nem tudo fica registrado" (1992, p. 203). Por isso o nosso esforço em registrar de forma textual as informações sobre esse período da história do Educandário Alzira Bley e de milhares de pessoas que já passaram por lá ao longo destes quase 80 anos. O que está em jogo na memória é também o sentido da identidade individual e do grupo (POLLAK, 1989).

Ainda que conseguíssemos ouvir as histórias de todos os ex-internos, não alcançaríamos replicar com clareza os sentimentos que permeiam as relações por eles estabelecidas, intra e extramuros do Educandário Alzira Bley. Podemos concluir apenas, que a instituição teve papel de grande importância na preservação da vida dessas pessoas e elas nutrem um carinho muito especial por esse lugar, como expressam Topázio e Jade.

Mas a gente gosta muito lá do Educandário. Até hoje a gente gosta. (Narrativa exinterno Topázio).

Foi bom, para mim tudo foi bom. E Graças à Deus, até hoje eu sou trabalhadeira 
(Narrativa da ex-interna Jade).

As grandes portas azuis estão abertas a todos aqueles que queiram contribuir com suas histórias, seus trabalhos, seus caminhos e suas memórias. Ressaltando que: "a memória nunca é uma reprodução exata dos acontecimentos do passado, mas sim um complicado, contraditório e contestado conjunto de representações" (THOMSON, 1998, p. 284).

\section{Considerações Finais}

A partir da criação do tripé de controle da profilaxia da lepra: leprosários/colônias agrícolas, preventórios/educandário e dispensários, os leprosos e sua prole indene passaram a ser isolados compulsoriamente por meio de legislação própria que estabelecia esta segregação, com aparatos policiais e subsídios públicos.

Nos preventórios/educandários, para onde eram destinados os filhos sadios dos leprosos, percebemos que o cotidiano das crianças era marcado pelo cumprimento de tarefas escolares, obrigações, trabalhos, momentos de lazer e festividades, mas também castigos corporais e sutilezas, marcando-as psicológica e emocionalmente. A saída da instituição para muitos internos não foi uma opção e sim uma imposição por causa da regra da maioridade ou em face do fim do regime de internação compulsória.

A reintrodução na sociedade e, muitas vezes, a introdução ao convívio familiar foi marcada por conflitos, na maior parte das vezes ocasionados pelo desconhecimento do outro. Depois de anos de separação em virtude da vida preventorial, viver em família significava, muitas vezes, revoltas, cobranças, atritos, que só foram superados pela reaprendizagem do convívio social e familiar. As consequências do internamento compulsório, em qualquer tipo de instituição, leprosário, colônias, ou preventórios, perduram até os dias atuais, conforme pudemos constatar no decorrer da pesquisa.

Os relatos dos narradores apontam para os acontecimentos que ficaram na memória como frutos de um processo seletivo/construtivo, os medos dentro do Educandário passavam muito mais pelos campos da necessidade (falta de alimentos, afetividade, falta dos pais) do que pelos castigos ou maus-tratos que, segundo os relatos, ficavam a cargo dos internos mais velhos (os guardiões) que tomavam conta dos mais novos e não propriamente dos empregados do Educandário.

No decorrer do processo de inserção na sociedade além dos muros, os ex-internos perceberam a dificuldade de se apresentarem como egressos do Educandário Alzira Bley, em virtude do estigma social em relação à lepra, apesar de eles nunca terem sido acometidos pela doença.

$\mathrm{Na}$ realidade, as pessoas que foram submetidas a esse processo de reclusão forçada mereciam ser compensadas, o Estado deveria responsabilizar-se pelas consequências da implantação da política pública que transformou de maneira profunda e irreversível a vida social de milhares de pessoas e violou os direitos das crianças e adolescentes internados compulsoriamente no Educandário Alzira Bley. A baixa escolaridade, a baixa autoestima, as dificuldades para manter-se empregados e nos relacionamentos familiares são algumas dessas "sequelas" apontadas pelos narradores.

Vale ressaltar que existe uma lacuna sobre a temática da vida dos internos nos Educandários e a sobre a reintrodução destas pessoas na sociedade após o fim da internação compulsória, sendo assim, esta pesquisa geográfica, e a Geografia enquanto Ciência da área Humana, tem muito a contribuir como o levantamento de informações e dados construídos sobre este segmento.

Podemos concluir que as políticas públicas no campo da lepra foram severas com o doente e seus familiares e que precisam existir medidas mais efetivas na busca pela 
redução dos danos e consequências diretas e indiretas resultantes do estigma e segregação dos filhos sadios, egressos dos preventórios, que partilham trajetórias semelhantes. Concluímos que a vida preventorial deixa marcas profundas na vida, no estigma e na memória dos egressos.

\section{Referências}

CABRAL, Ana Michele de farias. Vivências compartilhadas de filhos separados pela hanseníase no RN a luz da história oral de vida. 2013. 143 f. Dissertação de Mestrado em Enfermagem. Universidade Federal do Rio Grande do Norte. Natal, 2013.

CLAVAL, Paul. "A volta do cultural" na Geografia. Mercator - Revista de Geografia da UFC, ano 01 , número 1, 2002. Disponível em <http://www.mercator.ufc.br/index.php/mercator/article/viewArticle/192.>. Acesso em: 8 jan. 2017.

FARIA, Kalyna Ynanhiá Silva de. Da dignificação dos filhos de lázaros: um estudo sobre o Preventório Afrânio de Azevedo. Goiânia 1942-1950. 2014. 118 f. Dissertação de Mestrado em História. Universidade Federal de Goiás. Goiânia, 2014.

GINZBURG, Carlo. O Queijo e os Vermes. SP: Cia das Letras, 2006.

GOFFMAN, Erving. Estigma: notas sobre a manipulação da identidade deteriorada. 4. ed. Rio de janeiro: LTC, 1988.

LE GOFF, J. "Memória”. In: História e memória. Campinas: Editora da UNICAMP, 1994. p. 423-483.

MONTEIRO, Yara Nogueira. Hanseníase: história e poder no estado de São Paulo. Hansen Int., 12(1):1-7, 1987.

POLLAK, Michael. "Memória e identidade social". Estudos Históricos, Rio de Janeiro: CPDOC-FGV, v. 5, n. 10, p. 200-212, 1992.

POLLAK, Michael. "Memória, esquecimento, silêncio". Estudos Históricos, Rio de Janeiro: CPDOC-FGV, v. 2, n. 3, p. 3-15, 1989.

PORTELLI, Alessandro. "O que faz a história oral diferente". Proj. História, São Paulo, n. 14, p. 25-39, fev.1997.

PORTELLI, Alessandro. "A Filosofia e os fatos". Tempo, Rio de Janeiro: RelumeDumará, v. I, n. 2, p. 59-72, 1996.

THOMPSON, Paul. A voz do passado: história oral. 2. ed. Rio de Janeiro, Paz e Terra, 1998.

THOMSON, Alister. "Quando a memória é um campo de batalha: envolvimentos pessoais e políticos com o passado do exército nacional”. Proj. História, São Paulo, n. 16 p. $277-296$, fev. 1998. 